\title{
The Fuzzy Regression Approach to Peak Load Estimation in Power Distribution Systems
}

\author{
J. Nazarko, Member, IEEE \\ W. Zalewski \\ Division of Informatics, Control and Management in Electrical Power Engineering \\ Bialystok Technical University \\ Bialystok, Poland.
}

\begin{abstract}
This paper presents a new scheme based on the fuzzy regression analysis for the estimation of peak load in distribution systems. In distribution system, bus load estimation is complicated because system load is usually monitored at only a few points. As a rule receiving nodes are not equipped with stationary measuring instruments so measurements of loads are performed sporadically. In general, the only information commonly available regarding loads, other than major distribution substations and equipment installations, is billing cycle customer $\mathrm{kWh}$ consumption. In order to model system uncertainty, inexactness, and random nature of customers' demand, a fuzzy system approach is proposed. This paper presents possibilities of application of the fuzzy set theory to power distribution system calculations. Unreliable and inaccurate input data have been modeled by means of fuzzy numbers. Trapezoidal and triangular forms of fuzzy numbers were used for description of input data. A regression model, expressing the correlation between a substation peak load and a set of customer features (explanatory variables), existing in the substation population, is determined. Simulation studies have been performed to demonstrate the efficiency of the proposed scheme on the basis of actual data obtained at two distribution system substations. The same data have been used for building standard linear regression models. Comparison of the performance of both methods has been done.
\end{abstract}

Keywords: Fuzzy Set Theory, Fuzzy Regression Analysis, Load Estimation, Power Distribution Systems.

\section{INTRODUCTION}

The knowledge of loads at system buses is one of the most important requirements for efficient operation of power distribution systems [2, 5]. Estimation of loads, particularly of peak loads, is the basis for the system state estimation and for technical and economic calculations. This makes possible improvement in operation and maintenance of

PE-036-PWRS-0-08-1998 A paper recommended and approved by the IEEE Power System Analysis, Computing and Economics Committee of the IEEE Power Engineering Society for publication in the IEEE Transactions on Power Systems. Manuscript submitted January 9,1998; made available for printing August 14, 1998. electrical equipment and in planning of network operating configurations.

The main difficulties in the modeling of peak loads at receiving buses in distribution systems result from the random nature of loads, diversification of load shapes on different parts of the system, the deficiency of measured data and the fragmentary and uncertain character of information on loads and customers.

The uncertainty appears at the input, at the output and in the nature of the system itself and it is caused by:

$\checkmark$ the random character of the customers' demand for electrical power and energy,

- the influence of the random factor on the system,

- the fuzzy character of the control function, caused by the absence of the full formalization of aims of the system and by the presence of heuristic procedures in the decision process,

- the fuzzy character of the sets of the feasible system states, feasible controls and input information, caused by the uncertainty of corresponding a priori information.

The use of typical load shapes and additional information on customers (energy consumption in different periods, average level of utilization of rated power of transformers, single measurements of loads) in relation to the load modeling at distribution systems buses has been previously proposed [5]. Another approach consists in utilization of periodic energy consumed by customers who are divided into classes having different load shapes. A further approach is based on the employment of operational staff (experts) evaluations [5].

Essential weaknesses of proposed methods are:

- lack of precise definition of degree of likelihood of obtained estimators,

- disregard of fuzzy character of some factors which have an effect on load estimation.

In the present stage of development of power distribution systems, the mathematical estimation of the loads at the system buses seems to be the most realistic strategy due to incomplete primary information on loads and customers. It demands earlier determination of the stable relations between bus loads and easier available data [5].

The most renowned method for expressing the uncertainty in load models is fuzzy sets theory. 


\section{FUZZY MODELS}

Many factors such as loads and voltages at system buses, energy consumption, and parameters of equivalent circuits are included in power distribution systems calculations. This data is loaded with different errors arising from the inaccuracy of measuring instruments and deficiency of measurements. The theory which enables efficient description of unreliable and inaccurate data, and the relationship between them, is fuzzy set theory.

For the purpose of simplicity of mathematical operation the trapezoidal and triangular forms of fuzzy numbers are usually used (Fig. 1).
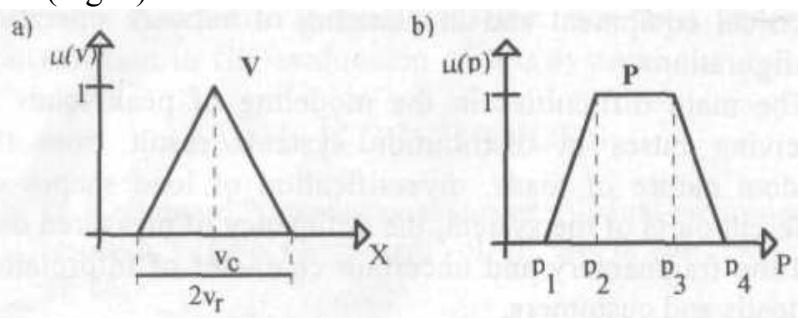

Fig, 1. Triangular and trapezoidal forms of fuzzy number

The subject literature introduces several ways of formation of the membership function $n$ of fuzzy number $[3,4,6]$. It is often possible, on the basis of expert experience, to define the parameters of fuzzy number $\mathrm{P}$ by means of linguistic variables. The proposed method may be applied for example to the description of the peak load at a receiving bus in the case where there is insufficiently accurate data and we only know that supplied customers belong to a given class of load.

- the value of $P$ is usually between $p_{2}$ and $p_{3}$,

- the value of $P$ is never above $p, »$,

- the value of $\mathrm{P}$ is never below pi.

Another method for description of a membership function is an application of data on the average value $a_{0}$ and maximum error $e$ of the input quantity. In practical applications we may describe in this way the values of voltages at transformer buses at a supplying point, or parameters of equivalent circuits of system elements. In this case parameters of fuzzy number can be defined as follows:

$$
\begin{array}{ll}
\mathrm{v}_{1}=a_{0}-e & \mathrm{v}_{2}=a_{0}-\frac{e}{2} \\
\mathrm{v}_{3}=a_{0}+\frac{e}{2} & \mathrm{v}_{4}=a_{0}+e
\end{array}
$$

Fuzzy numbers may be also formatted by using a mean value of a few measurements (if the number of measurements does not allow us to define parameters of variable distribution) [3]. If we have a sample $\{x j\}$ where $i=1,2, \ldots, n(n<30)$ then

$$
\begin{aligned}
& \mathrm{p}_{1}=\min \left\{\mathrm{x}_{\mathrm{i}}\right\} \quad \mathrm{p}_{2}=\mathrm{E}\left[\mathrm{x}_{\mathrm{i}}\right]-\left[\mathrm{E}\left[\mathrm{x}_{\mathrm{i}}\right]-\min \left\{\mathrm{x}_{\mathrm{i}}\right\}\right] \mathrm{d} \\
& \mathrm{p}_{3}=\mathrm{E}\left[\mathrm{x}_{\mathrm{i}}\right]+\left[\max \left\{\mathrm{x}_{\mathrm{i}}\right\}-\mathrm{E}\left[\mathrm{x}_{\mathrm{i}}\right]\right] d \quad \mathrm{p}_{4}=\max \left\{\mathrm{x}_{\mathrm{i}}\right\}
\end{aligned}
$$

where $E[x j]$-mean value of $x$ calculated from the sample, $d$ -factor of deviation, describing the degree of data uncertainty.

\section{FUZZY REGRESSION METHOD}

The general regression model is given by the following equations [1]:

$$
\mathrm{Y}=\mathbf{Z A}+\mathrm{e}
$$

where: $\mathrm{Y}$ - vector of output variables,

$\mathrm{Z}$ - matrix of independent variables,

A - vector of parameters,

e - vector of unobservable errors.

Two cases can be discriminated depending on the type of output variable. The first when the output variable (daily peak load $-\mathrm{P}_{\mathrm{dP}}$ ) is a real number and the second when the output value is an interval $\mathrm{P}_{\mathrm{dP}} \in<\mathrm{P}_{\mathrm{dP}}{ }^{\mathrm{L}}, \mathrm{P}_{\mathrm{dP}} \mathrm{R}^{\mathrm{P}}$ -

The first case can be represented in the form:

$$
\widetilde{\mathbf{P}}_{\mathrm{dP}}=\mathbf{Z} \tilde{\mathbf{A}}
$$

where:

$$
\widetilde{p}_{\mathrm{dpi}}\left(\mathrm{z}_{\mathrm{i}}\right)=\widetilde{\mathrm{a}}_{0}+\widetilde{\mathrm{a}}_{1} \mathrm{z}_{\mathrm{i} 1}+\cdots+\widetilde{\mathrm{a}}_{\mathrm{k}} \mathrm{z}_{\mathrm{ik}} \quad \mathrm{i}=1,2, \ldots, \mathrm{n}
$$

The linear fuzzy regression model (5) is represented using symmetric triangular fuzzy parameters $\mathrm{a},=\left[\mathrm{a}_{\mathrm{ic}}, \mathrm{a}_{\mathrm{lr}}\right]$ (Fig. 1) as follows:

$$
\begin{aligned}
& \widetilde{p}_{d P i}\left(z_{i}\right)=\left[a_{0 c}, a_{0 r}\right]+\left[a_{1 c}, a_{1 r}\right] z_{i 1}+\cdot+\left[a_{k c}, a_{k r}\right] z_{i k} \\
& p_{d P i c}\left(z_{i}\right)=a_{0 c}+a_{1 c} z_{i 1}+\cdot+a_{k c} z_{i k} \\
& p_{d p i r}\left(z_{i}\right)=a_{0 r}+a_{1 r} z_{i 1}+\cdot+a_{k r} z_{i k}
\end{aligned}
$$

where: $p_{d P c}, a_{c}-$ center parameters of fuzzy numbers (membership function $\mu=1$ ),

$\mathrm{P}_{\mathrm{dPr}}, \mathrm{a}_{\mathrm{r}}$ - spreads of fuzzy numbers (geometrically the spread is a half of the base of the triangle).

The parameters $a_{i}$ of the vector $A$ of the linear fuzzy regression model are determined by a solution of a linear programming (LP) problem which is to minimize the sum of spreads $P_{d p r}(Z i)$ of elements of vector $P_{d p}[8,9]$.

Therefore the following LP problem is formulated.

$$
\begin{array}{cl}
c=p_{d P I r}\left(z_{1}\right)+p_{d p_{2} r}\left(z_{2}\right)+\cdot+p_{d P n r}\left(z_{n}\right) \rightarrow \text { Minimum } \\
\text { subject to } & p_{d P i} \in \widetilde{P}_{d P}\left(z_{i}\right), \quad i=1,2, \ldots, n \\
& a_{i r} \geq 0, \quad i=0,1,2, \ldots, k
\end{array}
$$

From (6) - (8), the LP problem (9) - (11) can be written as follows:

$$
\sum_{\mathrm{i}=1}^{\mathrm{n}}\left(\mathrm{a}_{0 \mathrm{r}}+\mathrm{a}_{1 \mathrm{r}}\left|\mathrm{z}_{\mathrm{in}}\right|+\cdots+\mathrm{a}_{\mathrm{kr}}\left|\mathrm{z}_{\mathrm{ik}}\right|\right) \rightarrow \text { Minimum }
$$

the parameters of the fuzzy number are: 
$a_{0 c}+\sum_{j=1}^{\kappa}\left(a_{j c} z_{i j}\right)-a_{0 r}-\sum_{j=1}^{n}\left(a_{j r}\left|z_{i j}\right|\right) \leq p_{d P i}, i=1,2, \ldots, n$

$a_{0 c}+\sum_{j=1}^{k}\left(a_{j c} z_{i j}\right)+a_{0 r}+\sum_{j=1}^{k}\left(a_{j r}\left|z_{i j}\right|\right) \geq p_{d P i}, i=1,2, \ldots, n$

The parameters $a_{f}=\left[a j_{c}, a j\right]$ of vector $A$ are determined as the optimal solution of the LP problem (12) - (14). Since the LP problem always has feasible solutions, the fuzzy parameters are obtained from the LP problem for any data.

When the output value is an interval $\mathrm{P}_{\mathrm{dP}}$ e $<\mathrm{Pdp}^{\mathrm{L}}, \mathrm{Pdp}^{\mathrm{R}}>$ then the linear fuzzy model type of $\mathrm{P}_{\mathrm{dP}}=\mathrm{ZB}$ can be determined by means of trapezoidal fuzzy parameters.

In this case two models which can be determined by equations (6) - (8) were investigated:

- model for interval, where membership function $\mid x^{m} 1$, described by parameters $b_{c}{ }^{\prime}$ and $b_{r}{ }^{\prime}$, (Fig. 2)

$$
\widetilde{\mathrm{p}}_{\mathrm{dp}}^{1}\left(\mathrm{z}_{\mathrm{i}}\right)=\left[\mathrm{b}_{\mathrm{oc}}^{1}, \mathrm{~b}_{\mathrm{or}}^{1}\right]+\left[\mathrm{b}_{\mathrm{lc}}^{1}, \mathrm{~b}_{\mathrm{lr}}^{1}\right] \mathrm{z}_{\mathrm{il}}+\cdots+\left[\mathrm{b}_{\mathrm{kc}}^{1}, \mathrm{~b}_{\mathrm{kr}}^{1}\right] \mathrm{z}_{\mathrm{ik}}
$$

- model for interval, where membership function $\mu=\alpha$, described by parameters $b_{c}{ }^{\alpha}$ and $b_{r}{ }^{\alpha}, \alpha$-level set (Fig. 2),

$$
\widetilde{\mathrm{p}}_{\mathrm{dP} i}^{\mathrm{a}}\left(\mathrm{z}_{\mathrm{i}}\right)=\left[\mathrm{b}_{0 \mathrm{c}}^{\mathrm{a}}, \mathrm{b}_{\mathrm{Or}}^{\mathrm{a}}\right]+\left[\mathrm{b}_{\mathrm{ic}}^{\mathrm{a}}, \mathrm{b}_{1 \mathrm{r}}^{\mathrm{a}}\right] \mathrm{z}_{\mathrm{il}}+\cdots+\left[\mathrm{b}_{\mathrm{kc}}^{\mathrm{a}}, \mathrm{b}_{\mathrm{kr}}^{\mathrm{a}}\right] \mathrm{z}_{\mathrm{ik}}
$$

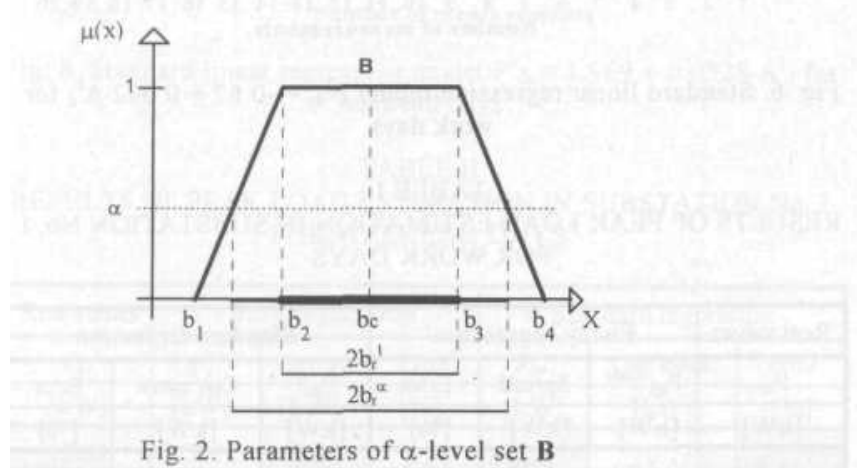

The LP formulation for determining the model (16) is the same as (9) - (11). In the case of model (15) the parameters bj of vector B are determined by the LP problem which is to maximize the sum of spreads $\left.\operatorname{Pdp}_{\mathrm{r}}{ }^{\prime}{ }^{z_{i}}\right)$ - The LP formulation for the model (15) is as follows [9].

$$
\begin{aligned}
\mathrm{c}=\mathrm{p}_{\mathrm{dPIr}}^{1}\left(\mathrm{z}_{1}\right)+\mathrm{p}_{\mathrm{dP} 2 \mathrm{r}}^{1}\left(\mathrm{z}_{2}\right)+\cdots+\mathrm{p}_{\mathrm{dPnr}}^{1}\left(\mathrm{z}_{\mathrm{n}}\right) \rightarrow \text { Maximum } \\
\text { subject to } \mathrm{p}_{\mathrm{dP} i}^{1} \in \widetilde{\mathrm{P}}_{\mathrm{dP}}\left(z_{i}\right), \quad \mathrm{i}=1,2, \ldots, \mathrm{n} \\
\mathrm{b}_{\text {ir }}^{1} \geq 0, \quad \mathrm{i}=0,1,2, \ldots, \mathrm{k}
\end{aligned}
$$

This LP problem is written as follows.

$$
\begin{gathered}
\sum_{i=1}^{n}\left(b_{0 r}^{1}+b_{1 r}^{1}\left|z_{i l}\right|+L+b_{k r}^{1}\left|z_{i k}\right|\right) \rightarrow \text { Maximum } \\
b_{0 c}^{1}+\sum_{j=1}^{k}\left(b_{j c}^{1} z_{i j}\right)-b_{0 r}^{1}-\sum_{j=1}^{k}\left(b_{j r}^{1}\left|z_{i j}\right|\right) \geq p_{d p i}^{L} i=1,2, \ldots, n
\end{gathered}
$$

$b_{0 c}^{1}+\sum_{j=1}^{k}\left(b_{j c}^{1} z_{i j}\right)+b_{0 r}^{1}+\sum_{j=1}^{k}\left(b_{j r}^{1}\left|z_{i j}\right|\right) \leq p_{d p i}^{R} \quad i=1,2, \ldots, n$

The parameters $b "$ are determined as the optimal solution of (16) LP problem. The parameters $b]$ are determined as the optimal solution of (15) LP problem. Since the LP problem (20) - (22) does not always have feasible solutions, there are cases where the linear model cannot be obtained from the given data. In these cases, the linear regression model should be replaced with a nonlinear model.

\section{APPLICATIONS OF THE FUZZY REGRESSION ANALYSIS TO THE ELECTRICAL LOAD ESTIMATION}

The loads on distribution transformers are the instantaneous summations of the individual demands of many customers. Since the pattern of electrical demand of each customer cannot be determined precisely, it is usually necessary to calculate system loadings on an estimation basis.

Planning engineers use load estimation to predict the loads on different parts of distribution systems.

The probabilistic models are widely used to estimate system loads. In order to develop the relevant types and parameters of probability distribution, large numbers of recorded consumption values are required. To obtain the above data a special measurement project has to be considered.

In practice the only information commonly available regarding loads, other a major distribution substations is $\mathrm{kWh}$ consumption.

Many relationships between output quantities (peak load, load flow, losses of power and energy) and describing values coming from measurements can be represented by a regression model. Results of investigations made on the basis of experimental design show that the energy consumption is the most correlated factor with the peak load demand [2, 5]. The use of statistical methods is not always possible due to occurrence of a large deficit of measurements. The fuzzy set theory is a convenient mathematical tool that allows us to partially eliminate unreliability from input information and to limit the influence of deficit of measurements.

The daily 15-minutes peak power consumption for a given substation may be found on the basis of $\mathrm{kWh}$ consumption using fuzzy regression models (5) and (15) - (16).

\section{NUMERICAL EXAMPLE}

To verify the proposed method of peak load estimation the measurements of daily energy consumption $\mathrm{Aj}$ and daily peak load $\mathrm{P}_{\mathrm{d}} \mathrm{p}$ at two selected distribution substations in Bialystok Power Distribution Utility Co. were made from January to April (substation No. I and No. II). The first of them supplies municipalcommercial customers. The second of them supplies municipalliving customers. The sample 24-hour load profiles for substation No. I are shown on Fig. 3 and Fig. 4. 


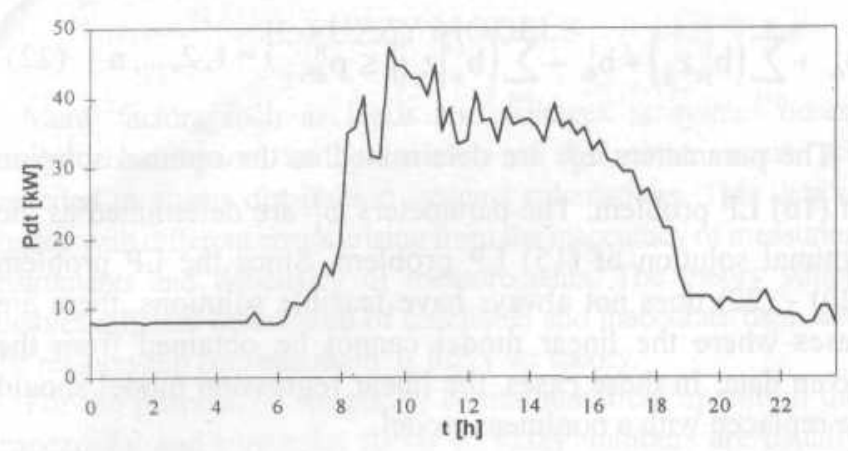

Fig. 3. Example of 24-hour load profile for substation No. I in work days

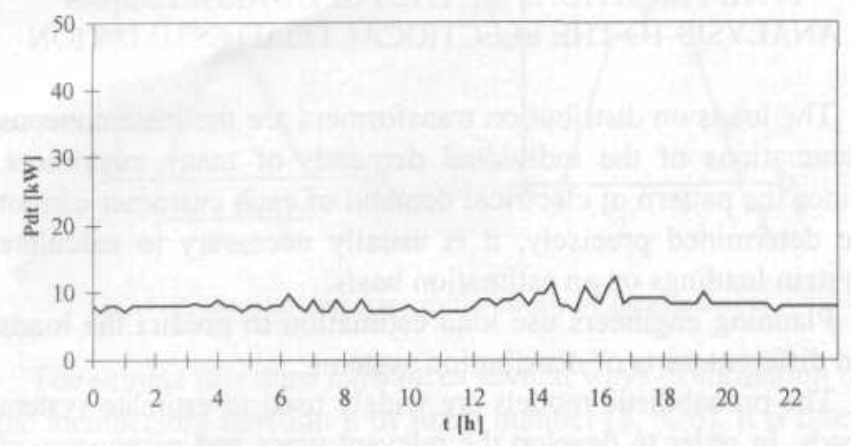

Fig. 4. Example of 24-hour load profile for substation No. I in weekend days

On this basis the fuzzy regression model for $A_{d}$ and $P_{d P}$, was determined as given by:

$$
\mathrm{P}_{\mathrm{dP}}=\left[\mathrm{a}_{\mathrm{Oc}}, \mathrm{a}_{\mathrm{Or}}\right]+\left[\mathrm{a}_{\mathrm{c}}, \mathrm{a}_{\mathrm{rl}}\right] * \mathrm{~A}_{\mathrm{d}}
$$

where: $\mathrm{P}_{\mathrm{dp}}$ - the daily 15 -minutes peak power consumption,

$A_{d}$ - the daily energy consumption.

Two models for the selected two types of days (work and weekend days) were calculated. The LP problem corresponding to the given data was formulated from (12) - (14). By solving this LP problem, the following fuzzy regression models for substation No. I and No. II are obtained:

- for substation No. I and work days (sample size $=30$ )

$$
\mathrm{P}_{\mathrm{ds}}^{\prime}=[-7.0129,0.0]+[0.103028,0.009572]-\mathrm{A}_{\mathrm{d}}^{1}
$$

- for substation No. I and weekend days (sample size $=10$ )

$$
\mathrm{P}_{\mathrm{ds}}^{\prime}=[4.170909,2.943204]+[0.046017,0.0] \mathrm{A}_{\mathrm{d}}^{\prime}
$$

- for substation No. II and work days (sample size $=30$ )

$$
\mathrm{P}^{\prime \prime}{ }_{\mathrm{ds}}=[10.8492,1.9603]+[0.07101,0.0051] \mathrm{A}_{\mathrm{d}}^{1 \mathrm{I}}
$$

- for substation No. II and weekend days (sample size $=10$ )

$$
\mathrm{P}_{\mathrm{ds}}=[-2.0277,0.1721]+[0.08845,0.0031]-\mathrm{A}_{\mathrm{d}}^{\mathrm{II}}
$$

On the basis of models (24) - (27) daily peak loads at the same substations in a period of three weeks in May were estimated. The same data were used for building standard regression models [1]. The 95 per cent confidence interval was used as a measure of statistical uncertainty. Then daily peak load in the same cases as in the fuzzy approach were estimated. The results are shown in Tables I - IV and Fig. 5-12 together with the corresponding measurements data.

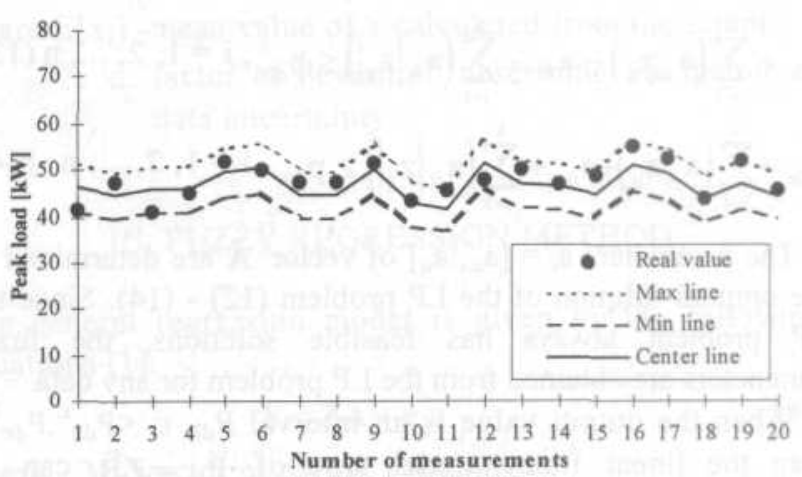

Fig. 5. Linear fuzzy regression model $\mathrm{P}_{d s}=f\left(A_{d}^{1}\right)$ for work days

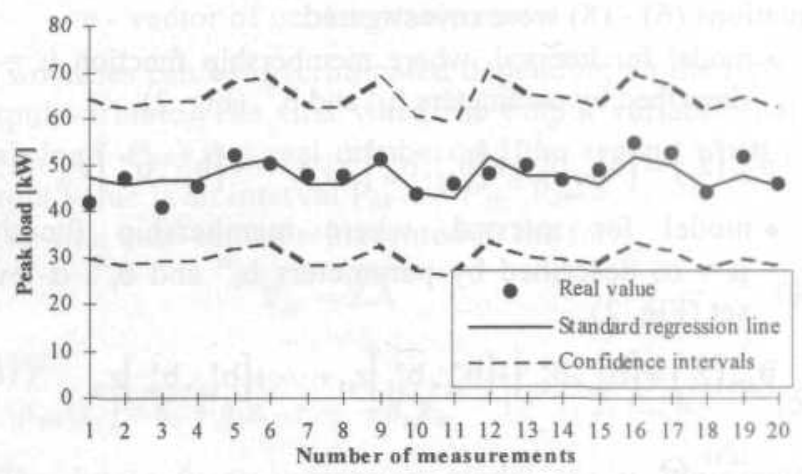

Fig. 6. Standard linear regression model $\mathrm{P}_{\mathrm{ds}}^{\mathrm{d}}=-0.67+0.092 \cdot \mathrm{A}_{\mathrm{d}}^{\mathrm{d}}$ for work days

TABLE I

RESULTS OF PEAK LOAD ESTIMATION IN SUBSTATION No. I FOR WORK DAYS

\begin{tabular}{|c|c|c|c|c|c|c|}
\hline Real values & \multicolumn{3}{|c|}{ Fuzzy regression } & \multicolumn{3}{c|}{ Standard regression } \\
\hline $\mathrm{P}_{\mathrm{dp}}$ & $\mathrm{P}_{\mathrm{dp}}^{{ }^{\text {tentt }}}$ & Spread & Error & $\mathrm{P}_{\mathrm{dp}}{ }^{\circ}$ & Con. interv. & Error \\
\hline$[\mathrm{kW}]$ & {$[\mathrm{kW}]$} & {$[\mathrm{kW}]$} & {$[\%]$} & {$[\mathrm{kW}]$} & {$[\mathrm{kW}]$} & {$[\%]$} \\
\hline 41.71 & 46.29 & 4.95 & -10.98 & 47.09 & 17.43 & -12.90 \\
\hline 47.33 & 44.62 & 4.80 & 5.72 & 45.60 & 17.15 & 3.66 \\
\hline 40.92 & 45.83 & 4.91 & -12.00 & 46.68 & 17.35 & -14.08 \\
\hline 45.29 & 46.01 & 4.93 & -1.58 & 46.84 & 17.38 & -3.42 \\
\hline 51.82 & 49.51 & 5.25 & 4.45 & 49.98 & 17.96 & 3.55 \\
\hline 50.08 & 50.69 & 5.36 & -1.23 & 51.04 & 18.16 & -1.91 \\
\hline 47.48 & 44.70 & 4.80 & 5.86 & 45.66 & 17.16 & 3.82 \\
\hline 47.42 & 44.71 & 4.81 & 5.71 & 45.68 & 17.16 & 3.68 \\
\hline 51.27 & 50.16 & 5.31 & 2.16 & 50.56 & 18.07 & 1.38 \\
\hline 43.53 & 42.80 & 4.63 & 1.67 & 43.97 & 16.85 & -1.00 \\
\hline 45.62 & 41.44 & 4.50 & 9.16 & 42.75 & 16.62 & 6.30 \\
\hline 47.85 & 51.50 & 5.44 & -7.64 & 51.76 & 18.29 & -8.18 \\
\hline 49.88 & 46.87 & 5.01 & 6.03 & 47.61 & 17.52 & 4.55 \\
\hline 46.85 & 46.55 & 4.98 & 0.62 & 47.33 & 17.47 & -1.03 \\
\hline 48.82 & 44.60 & 4.80 & 8.63 & 45.58 & 17.15 & 6.63 \\
\hline 54.83 & 51.08 & 5.40 & 6.84 & 51.39 & 18.22 & 6.28 \\
\hline 52.3 & 49.15 & 5.22 & 6.02 & 49.66 & 17.90 & 5.06 \\
\hline 43.97 & 43.62 & 4.70 & 0.78 & 44.71 & 16.98 & -1.68 \\
\hline 51.72 & 46.72 & 4.99 & 9.65 & 47.48 & 17.50 & 8.19 \\
\hline 45.68 & 44.42 & 4.78 & 2.75 & 45.42 & 17.12 & 0.57 \\
\hline & & & & & & \\
\hline
\end{tabular}




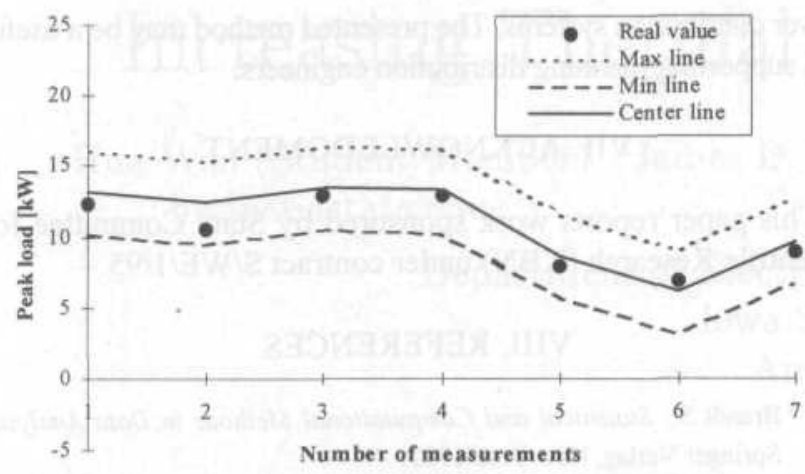

Fig. 7. Linear fuzzy regression model $P_{d s}^{\prime}=f\left(A_{d}^{\prime}\right)$ for weekend days

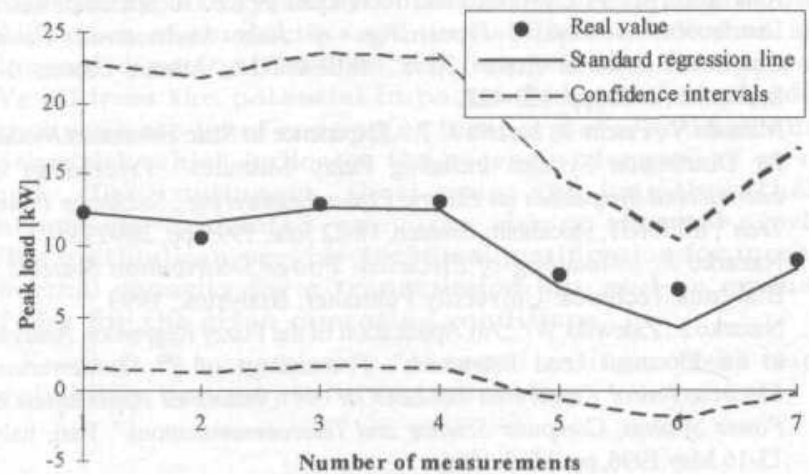

Fig. 8. Standard linear regression model $\mathrm{P}_{\mathrm{ds}}^{1}=1.969+0.0528 \cdot \mathrm{A}_{\mathrm{d}}^{\mathrm{d}}$ for weekend days

TABLE II

RESULTS OF PEAK LOAD ESTIMATION IN SUBSTATION No. I FOR WEEKEND DAYS

\begin{tabular}{|c|c|c|c|c|c|c|}
\hline Real values & \multicolumn{3}{|c|}{ Fuzzy regression } & \multicolumn{3}{c|}{ Standard regression } \\
\hline $\mathrm{P}_{\mathrm{dP}}$ & $\mathrm{P}_{\mathrm{dp}}{ }^{\text {trents }}$ & Spread & Error & $\mathrm{P}_{\mathrm{dp}}{ }^{\prime}$ & Con, interv. & Error \\
\hline$[\mathrm{kW}]$ & {$[\mathrm{kW}]$} & {$[\mathrm{kW}]$} & {$[\%]$} & {$[\mathrm{kW}]$} & {$[\mathrm{kW}]$} & {$[\%]$} \\
\hline 12.31 & 13.11 & 2.94 & -6.53 & 12.24 & 10.73 & 0.57 \\
\hline 10.48 & 12.47 & 2.94 & -18.98 & 11.50 & 10.30 & -9.72 \\
\hline 12.84 & 13.42 & 2.94 & -4.48 & 12.59 & 10.93 & 1.99 \\
\hline 12.90 & 13.23 & 2.94 & -2.56 & 12.37 & 10.80 & 4.09 \\
\hline 7.83 & 8.59 & 2.94 & -9.69 & 11.02 & 10.03 & 10.06 \\
\hline 6.84 & 6.14 & 2.94 & 10.17 & 9.00 & 8.87 & 38.08 \\
\hline 8.91 & 9.69 & 2.94 & -8.79 & 8.13 & 8.37 & 6.73 \\
\hline
\end{tabular}

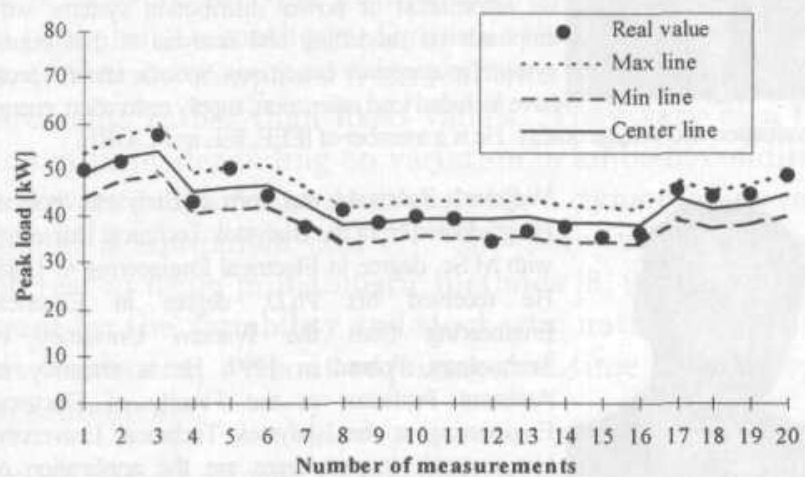

Fig. 9. Linear fuzzy regression model $\mathrm{P}_{\mathrm{ds}}^{\mathrm{I}}=\mathrm{f}\left(\mathrm{A}_{\mathrm{d}}^{\mathrm{II}}\right)$ for work days

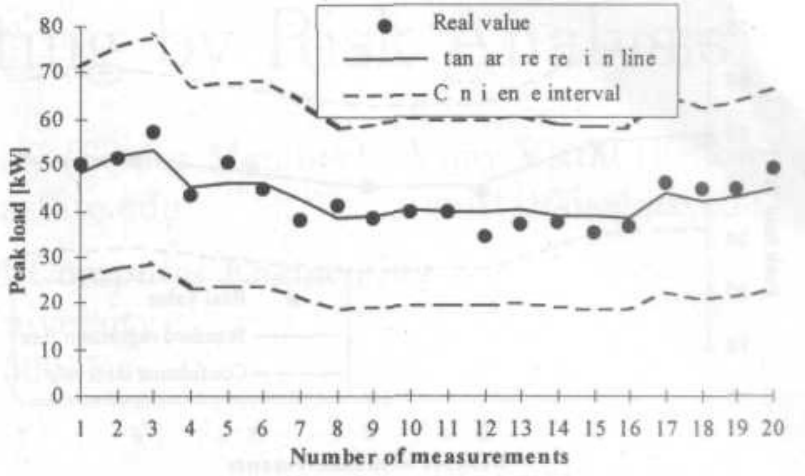

Fig. 10. Standard linear regression model $\mathrm{P}_{\mathrm{ds}}^{\mathrm{II}}=13.525+0.065 \cdot \mathrm{A}_{\mathrm{d}}^{\mathrm{II}}$ for work days

TABLE III

RESULTS OF PEAK LOAD ESTIMATION IN SUBSTATION No. II FOR WORK DAYS

\begin{tabular}{|c|c|c|c|c|c|c|}
\hline Real values & \multicolumn{3}{|c|}{ Fuzzy regression } & \multicolumn{3}{c|}{ Standard regression } \\
\hline$P_{\mathrm{dp}}$ & $P_{\mathrm{dp}}{ }^{\text {ceentr }}$ & Spread & Error & $\mathrm{P}_{\mathrm{dp}}{ }^{{ }^{\prime}}$ & Con. interv. & Error \\
\hline$[\mathrm{kW}]$ & {$[\mathrm{kW}]$} & {$[\mathrm{kW}]$} & {$[\%]$} & {$[\mathrm{kW}]$} & {$[\mathrm{kW}]$} & {$[\%]$} \\
\hline 50.05 & 48.91 & 4.67 & 2.28 & 48.37 & 23.06 & 3.36 \\
\hline 51.49 & 52.56 & 4.93 & -2.07 & 51.71 & 24.17 & -0.43 \\
\hline 57.36 & 54.08 & 5.04 & 5.73 & 53.10 & 24.63 & 7.43 \\
\hline 43.35 & 45.18 & 4.40 & -4.23 & 44.96 & 21.93 & -3.71 \\
\hline 50.43 & 46.21 & 4.48 & 8.36 & 45.90 & 22.24 & 8.98 \\
\hline 44.5 & 46.54 & 4.50 & -4.59 & 46.20 & 22.34 & -3.83 \\
\hline 37.84 & 42.69 & 4.23 & -12.81 & 42.67 & 21.17 & -12.77 \\
\hline 41.24 & 37.98 & 3.89 & 7.89 & 38.37 & 19.74 & 6.97 \\
\hline 38.6 & 38.73 & 3.94 & -0.33 & 39.05 & 19.96 & -1.16 \\
\hline 39.98 & 39.77 & 4.02 & 0.52 & 40.00 & 20.28 & -0.06 \\
\hline 39.74 & 39.40 & 3.99 & 0.85 & 39.67 & 20.17 & 0.18 \\
\hline 34.63 & 39.50 & 4.00 & -14.05 & 39.75 & 20.20 & -14.79 \\
\hline 37.03 & 40.07 & 4.04 & -8.21 & 40.28 & 20.37 & -8.77 \\
\hline 37.57 & 38.63 & 3.94 & -2.83 & 38.96 & 19.93 & -3.70 \\
\hline 35.3 & 38.50 & 3.93 & -9.06 & 38.84 & 19.89 & -10.02 \\
\hline 36.61 & 38.07 & 3.90 & -3.99 & 38.45 & 19.76 & -5.02 \\
\hline 45.96 & 43.90 & 4.31 & 4.49 & 43.78 & 21.53 & 4.74 \\
\hline 44.65 & 41.75 & 4.16 & 6.49 & 41.82 & 20.88 & 6.34 \\
\hline 44.73 & 42.88 & 4.24 & 4.14 & 42.85 & 21.22 & 4.21 \\
\hline 49.16 & 44.97 & 4.39 & 8.52 & 44.76 & 21.86 & 8.94 \\
\hline & & & & & & \\
\hline
\end{tabular}

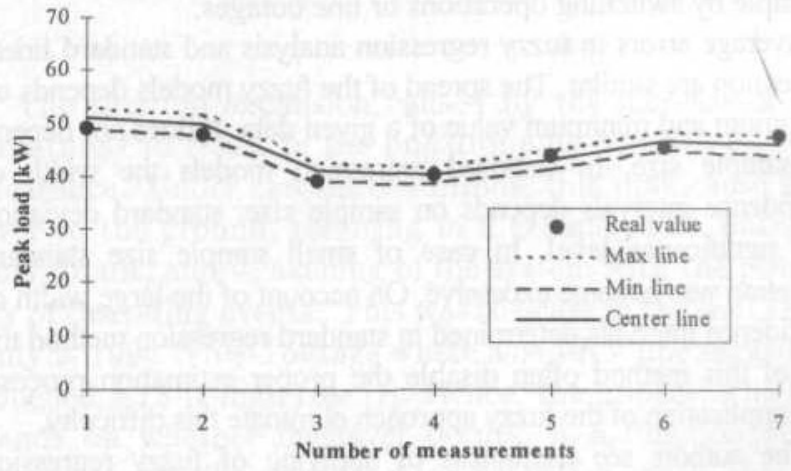

Fig. 11. Linear fuzzy regression model $\mathrm{P}_{\mathrm{ds}^{\prime \prime}}=f\left(\mathrm{~A}_{\mathrm{d}}{ }_{\mathrm{d}}\right)$ for weekend days 


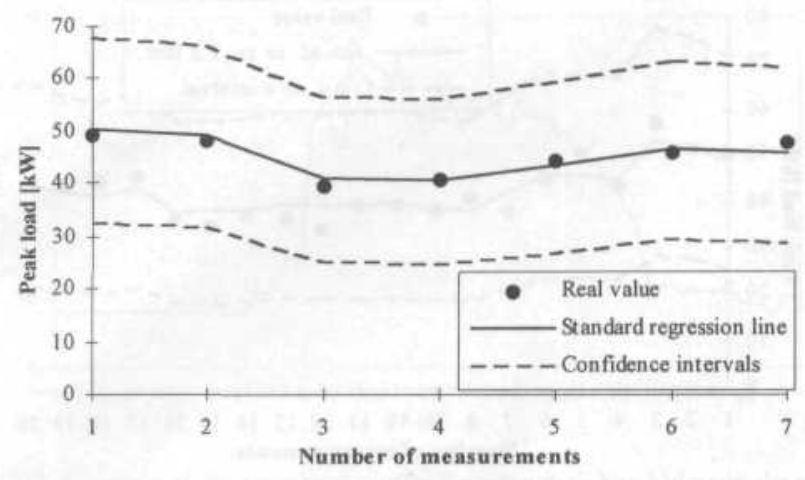

Fig. 12. Standard linear regression model $\mathrm{P}_{\mathrm{ds}}=1.052+0.0822 \cdot \mathrm{A}_{\mathrm{d}}{ }_{\mathrm{d}}$ for weekend days

TABLE IV

RESULTS OF PEAK LOAD ESTIMATION IN SUBSTATION No. II FOR WEEKEND DAYS

\begin{tabular}{|c|c|c|c|c|c|c|}
\hline Real values & \multicolumn{3}{|c|}{ Fuzzy regression } & \multicolumn{3}{c|}{ Standard regression } \\
\hline$P_{\mathrm{dp}}$ & $P_{\mathrm{dp}}{ }^{\text {,centr }}$ & Spread & Error & $\mathrm{P}_{\mathrm{dp}}{ }^{\prime}$ & Con. interv. & Error \\
\hline$[\mathrm{kW}]$ & {$[\mathrm{kW}]$} & {$[\mathrm{kW}]$} & {$[\%]$} & {$[\mathrm{kW}]$} & {$[\mathrm{kW}]$} & {$[\%]$} \\
\hline 49.12 & 50.92 & 2.00 & -3.67 & 50.28 & 17.58 & -2.36 \\
\hline 47.79 & 49.75 & 1.96 & -4.10 & 49.19 & 17.37 & -2.92 \\
\hline 39.28 & 40.94 & 1.66 & -4.21 & 40.99 & 15.82 & -4.36 \\
\hline 40.43 & 40.31 & 1.63 & 0.30 & 40.41 & 15.71 & 0.05 \\
\hline 44.08 & 43.25 & 1.74 & 1.88 & 43.14 & 16.23 & 2.12 \\
\hline 45.45 & 46.83 & 1.86 & -3.05 & 46.48 & 16.86 & -2.26 \\
\hline 47.59 & 45.77 & 1.82 & 3.83 & 45.49 & 16.67 & 4.42 \\
\hline
\end{tabular}

\section{CONCLUSIONS}

It is seen from the considerations and relationships described above that the fuzzy set approach to electrical load estimation puts a new quality into the system analysis in uncertain conditions. Owing to adequacy and simplicity it can be easily adapted to practical algorithms based on available data which may contain different types of errors.

The proposed method allows us to estimate daily 15-minutes peak power demand at distribution transformers during normal state conditions, on the basis of $\mathrm{kWh}$ consumption. The method does not handle the instantaneous loads changes caused for example by switching operations or line outages.

Average errors in fuzzy regression analysis and standard linear regression are similar. The spread of the fuzzy models depends on maximum and minimum value of a given data. It does not depend on sample size. In standard regression models the width of confidence intervals depends on sample size, standard deviation and significance level. In case of small sample size standard deviation was become excessive. On account of the large width of confidence intervals determined in standard regression method the use of this method often disable the proper estimation process. The application of the fuzzy approach eliminate this difficulty.

The authors see usefulness of applying of fuzzy regression method to problems of load forecasting and load estimation in power distribution systems. The presented method may be a useful tool supporting planning distribution engineers.

\section{ACKNOWLEDGMENT}

This paper reports work sponsored by State Committee for Scientific Research (KBN) under contract S/WE/1/95.

\section{REFERENCES}

[ 1] Brandt S.: Statistical and Computational Methods in Data Analysis. Springer Verlag, New York 1997.

[ 2] Kujszczyk Sz.: „Elektroenergetyczne sieci rozdzielcze”. PWN, Warszawa 1994. (In Polish)

[3] Kauhanieni K.: „Fuzzy Models and Techniques for the Calculation of Radial Distribution Networks". Proceedings of Joint International Power Conference „Athens Power Tech", IEEE/NTUA, Athens, Greece, 5-8 September, 1993, pp. 423-428.

[4] Miranda V., Pereira J., Saraiva J. T.: Experience in State Estimation Models for Distribution Systems Including Fuzzy Measures". Proceedings of International Symposium on Electric Power Engineering ,, Stockholm Power Tech", IEEE/RIT, Stockholm, Sweden, 18-22 June, 1995, pp. 288-293.

[ 5] Nazarko J.: ..Modeling of Electrical Power Distribution Systems". Bialystok Technical University Publisher, Bialystok, 1993.

[ 6] Nazarko J., Zalewski W.: ,A $\mathrm{A}^{\mathrm{n}}$ Application of the Fuzzy Regression Analysis to the Electrical Load Estimation". Proceedings of 8? Mediterranean Electrotechnical Conference MELECON '96 ..Industrial Applications in Power Systems, Computer Science and Telecommunications". Ban, Italy, 13-16 May 1996, pp. 1563-1566.

[ 7] Nazarko J., Zalewski W.: „The Fuzzy Set Approach to Substation Peak Load Estimation". Proceedings of 31" Universities Power Engineering Conference UPEC'96, Iraklio, Greece, September 18-20,1996, pp. 1291-1294.

[ 8] Tanaka H., Uejima S., Asai K.: „Linear Regression Analysis with Fuzzy Model". IEEE Transactions on Systems, Man and Cybernetics, Vol. 12, No. 6, December 1982, pp. 903-906.

[9] Tanaka H., Ischibuchi H.: ..Possibilistic Regression Analysis Based on Linear Programming” in „Fuzzy Regression Analysis" (eds. J. Kacprzyk, M. Fedrizzi), Physica-Verlag, Heidelberg, 1992, pp.47-60.

\section{BIOGRAPHIES}

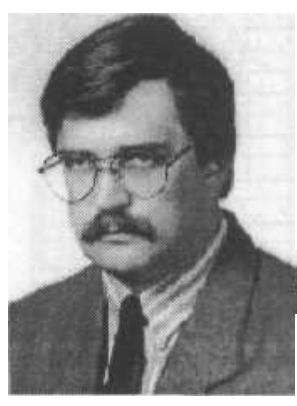

Joanicjusz Nazarko was bom in Michalowo, Poland. He received his $\mathrm{Ph} . \mathrm{D}$. and D.Sc. degrees in Electrical Engineering from the Warsaw University of Technology in 1983 and 1992, respectively. He is currently an Associate Professor of Electrical Engineering at the Bialystok Technical University, Poland and he serves as the head of Division of Informatics, Control and Management in Electrical, Power Engineering. His research activity is centered Ion automation of power distribution systems with I emphasis on modelling and analysis of distribution I systems in uncertain conditions. Specific research areas ' have included load estimation, supply restoration, energy loss evaluation and voltage quality. He is a member of IEEE, IEE and CIGRE.

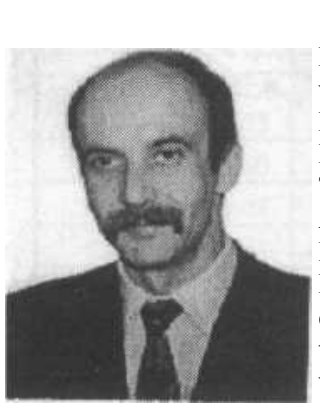

Wojciech Zalewski was born in Bialystok, Poland. He graduated from the Bialystok Technical Universitv with M.Sc. degree in Electrical Engineering in 1988. He received his $\mathrm{Ph} . \mathrm{D}$. degree in Electrical Engineering from the Warsaw University of Technology, Poland in 1997. He is presently an Assistant Professor at the Faculty of Electrical Engineering at the Bialystok Technical University. His research interest areas are the application of expert systems, and probabilistic and fuzzy concepts to power distribution systems modelling and analysis with emphasis on load estimation. 